ECOLOGICA, Vol. 28, No 103 (2021), 403-409

https://doi.org/10.18485/ecologica.2021.28.103.10

Originalni naučni rad

UDC: $37.033: 502.131$

\title{
Ekološki barometar: instrument utvrđivanja percepcije problema životne sredine
}

\section{Ecological barometer: an instrument for determining the perception of environmental problems}

\author{
Dejan Mandić1 ${ }^{*}$, Mesud Adžemović ${ }^{2}$, Jelena Milovanović ${ }^{3}$ \\ 1,2,3Univerzitet Singidunum, Danijelova 32, Beograd, Srbija / \\ Singidunum University, Danijelova 32, Belgrade, Serbia \\ *Autor za prepisku / Corresponding author
}

Rad primljen / Received: 06.12.2020, Rad prihvaćen / Accepted: 09.08.2021.

Sažetak: Ekološki problemi u nas nisu nestali, već se kumuliraju i istrajavaju. Percepcija ekoloških problema o ključnim medijima životne sredine (zagađenja vazduha, vode, hrane, smanjenje površine obradivog zemljišta i šuma, devastacija prirodnih resursa, generisanje i gomilanje otpada, klimatske promene) pokazuje zabrinjavajući trend. Rezultati su dobijeni sprovođenjem istraživanja, na uzorku od 236 ispitanika, 2015. i 2020. godine, primenom instrumenta sa 11 tvrdnji. Metodom multivarijantne analize, došlo se do razdvajanja „klasičnih“ i „novih“ faktora ekoloških problema, s tim da su utvrđeni korelativi ovih faktora sa ekološkim orijentacijama antropocentrizma, tehnocentrizma i ekocentrizma. Rezultati istraživanja pokazuju neophodnost objektivizacije subjektivnih stavova pojedinaca, uvođenjem ekološkog barometra, kao instrumentarijuma za utvrđivanje realne percepcije ekoloških problema i ekološke zabrinutosti u nas.

Ključne reči: ekološki problemi, zagađenje, stepen zabrinutosti, regionalne razlike.

\begin{abstract}
Environmental problems in our country have not disappeared, but are accumulating and persisting. The perception of environmental problems about key environmental media (air, water, food pollution, reduction of arable land and forests, devastation of natural resources, waste generation and accumulation, climate change) shows a worrying trend. The results were obtained by conducting research, on a sample of 236 respondents, 2015 and 2020 years, using an instrument with 11 statements. The method of multivariate analysis led to the separation of "classical" and "new" factors of environmental problems, with the correlations of these factors with the ecological orientations of anthropocentrism, technocentrism and ecocentrism being determined. The results of the research, obtained on the basis of the sample, show the necessity of objectifying the subjective attitudes of individuals by introducing the ecological barometer, as an instrument for determining the real perception of ecological problems and ecological concerns in our country.
\end{abstract}

Keywords: ecological problems, pollution, degree of concern, regional disparities.

${ }^{1}$ orcid.org/0000-0002-2473-862X, e-mail: dejan.mandic.19@singimail.rs

2orcid.org/0000-0002-3601-4485, e-mail: madzemovic@singidunum.ac.rs

${ }^{3}$ orcid.org/0000-0001-5310-5779, e-mail: jmilovanovic@singidunum.ac.rs 


\section{UVOD / INTRODUCTION}

Ekološka istraživanja su postala deo uobičajene prakse, ne samo razvijenih, već i tranzicionih društava. U Srbiji su retka ili sporadična istraživanja percepcije ekoloških problema. I onda kada su sprovođena, ta istraživanja nisu bila u funkciji donošenja pravovremenih ili realističnih odluka u ekološkoj politici, već u sklopu ili okvir(ima)u istraživanja o drugim pitanjima. Sasvim je izvesno da je stepen ekološke senzibilnosti u Srbiji porastao poslednjih decenija i zato empirijska istraživanja mogu u dobroj meri dati odgovore na sve veći broj pitanja o odnosu prema ekološkim problemima ili nekoj rizičnoj situaciji, odnosno mogu precizno karakterizovati sociokulturni kontekst reakcije populacije.

Ekološki problemi, iako specifični, mogu se rešavati pod uslovom da se identifikuju i otklone uzroci. Spektar ekoloških problema u oblasti zagađenja životne sredine je veliki: od zagađenja vazduha, vode, zemljišta, sve do uticaja na klimatske promene ili smanjenje biološke raznovrsnosti. Sukcesivnost je ključno obeležje nastanka ekoloških problema, kao posledice tehnološkog razvoja. Dijagnostifikovanje ekoloških problema sledi po pravilu onda kada oni ugroze ili na vidljiv način počinju da ugrožavaju zdravlje ljudi. Tek nakon toga bi usledile ili mogu da uslede ekološki prihvatljive mere zaštite, koje često ne daju dobre rezultate iz razloga što se ekološki problemi, zbog ubrzanog naučno-tehnološkog razvoja, iznova kumuliraju.

Čovek se prema ekološkim rizicima i problemima odnosi tako da ih precenjuje ili potcenjuje, a naučni diskurs teži ka tome da se objektivizuju subjektivne procene. Procena pojedinca o zabrinutosti za neki ekološki problem zavisi ne samo od subjektivnog stava onog ko procenjuje, već i od objektivne strane problema, koji utiče na procenu. Zbog toga je veliki značaj javnosti, koja utiče na ponašanje pojedinaca, njihov aktivizam ili deklarativnu podršku zaštiti životne sredine.

Ekološki problemi objektivno postoje nezavisno od subjektivne strane, odnosno percepcije pojedinca. Nije tako retko da društvo ili pojedinci ne percipiraju značajne ekološke probleme, ali i da istovremeno manje zabrinjavajuće ekološke probleme percipiraju kao veoma značajne. Često se dešava da nije toliko značajna veličina problema naspram tome kako taj isti problem percipira javnost. Zbog toga, istraživanje nije imalo za cilj koliko je stvarno zagađenje životne sredine ili njenih pojedinih medija, već percepcija odnosno procena ispitanika o stepenu zabrinutosti za ekološke probleme u društvu. Izvestan stepen zagađenja nužno postoji, kao rezultat privredne i drugih aktivnosti, što bi trebalo da bude svojevrsna ekološka cena razvijenosti. Međutim, ekološke preferencije se ne uspostavljaju samo i isključivo prema ekonomskim rezonima, jer na to snažan uticaj imaju opštekorisne vrednosti (Adžemović, 2016).

\section{MATERIJALI I METODE / MATERIALS AND METHODS}

Za prikupljanje podataka o značaju i ulozi socijalne dimenzije održivosti, percepcije ekoloških problema i uloge naučno-stručne javnosti u oblikovanju instrumentarijuma i mehanizama zaštite životne sredine korišćena je ciljana anketa, koja je sprovedena on-line tehnikom na uzorku od 236 ispitanika 2015. i 2020. godine (Adžemović i dr., 2017).

Istraživanje je obuhvatilo 236 ispitanika sledeće obrazovne strukture: $25 \mathrm{dr}$ nauka, $82 \mathrm{mr}$ i mastera, 86 VII stepena obrazovanja, 17 učesnika VI stepena obrazovanja, 8 ispitanika V stepena obrazovanja i 16 onih sa srednješkolskim obrazovanjem. Jedan od ciljeva istraživanja bio je da o instrumentima i sistemu zaštite životne sredine svoje stavove iskaže naučna i stručna javnost, organi lokalne samouprave u sektoru životne sredine, kao i organizacije civilnog društva proekološke orijentacije (Stevanović i dr., 2018).

Prilikom kreiranja ankete, imalo se u vidu da se relevantnost i kompetentnost stavova ne mere samo i isključivo obrazovnim nivoom ispitanika, ali i da je nivo obrazovanja solidna osnova za tvrdnju da su odgovori ispitanika reprezentativan stav stručne javnosti o otvorenim pitanjima savremene ekološke stvarnosti. Dobijeni rezultati su obrađeni pomoću programskog softvera SPSS (Statistical Package for the Social Sciences), zatim kombinovanjem metoda ispitivanja, metodom multivarijantne analize i analizom sadržaja dokumenata (Adžemović, 2019).

Ravnomerna regionalna zastupljenost (Beograd, Vojvodina, Istočna, Centralna, Zapadna i Južna Srbija) ispitanika bila je od velikog značaj, jer je omogućila uvid u sličnosti, odnosno razlike u proceni i percepciji ekološke senzibilnosti.

\section{REZULTATI I DISKUSIJA / RESULTS AND DISCUSSION}

Distribucija svih odgovora pokazuje pozitivnu asimetričnost (prikaz je dat u Tabeli 1), jer se ispitanici uglavnom opredeljuju za odgovore da su ekološki problemi "mnogo" i "veoma mnogo" zabrinjavajući. Zbir ovih odgovora (kolone $4+5$ ) je samo kod tri tvrdnje ispod $50 \%$ (zagađenje voda za piće, zagađenje reka i jezera, devastacija i odumiranje šuma), dok je u nekim tvrdnjama procenat ispitanika dostigao $75,2 \%$ (neadekvatno upravljanje komunalnim otpadom). Dominantne frekvencije su odgovori "mnogo" u koloni 4, a ekstremno pozitivni odgovori "veoma mnogo" su značajno manje zastupljeni. Rezulati pokazuju da je najviši stepen zabrinutosti kod neadekvatnog 
upravljanja komunalnim otpadom (t. $10-75,2 \%$ ), zagađenja hrane - pesticidi, herbicidi, konzervansi,

GMO (t.7 - 61,8\%) i ugroženosti životne sredine od industrijskih postrojenja (t.3 - 59,7\%).

Tabela 1 - Frekvencije zabrinutosti za ekološke probleme

Table 1 - Frequencies of concern for environmental issues

\begin{tabular}{|c|l|c|c|c|c|c|}
\hline \multirow{2}{*}{$\begin{array}{l}\text { Red br. } \\
\text { komponente }\end{array}$} & \multicolumn{1}{|c|}{ Sadržaj tvrdnje (varijable) } & \multicolumn{5}{|c|}{ Zabrinjavajući problem* } \\
\cline { 3 - 7 } & Zagađenje vazduha & 2,5 & 16,8 & 29,4 & 33,6 & 17,7 \\
\hline 1. & Zpasan otpad i njegovo gomilanje & 3,8 & 12,6 & 25,2 & 46,2 & 12,2 \\
\hline 2. & $\begin{array}{l}\text { Opdustrijski i medicinski) } \\
\text { (ind }\end{array}$ & 2,5 & 10,5 & 27,3 & 39,9 & 19,8 \\
\hline 3. & $\begin{array}{l}\text { Ugroženost životne sredine } \\
\text { od industrijskih postrojenja }\end{array}$ & 2,9 & 14,7 & 25,6 & 44,1 & 12.7 \\
\hline 4. & $\begin{array}{l}\text { Eksploatacija prirodnih resursa } \\
\text { (ugalj, šume, voda, nafta) }\end{array}$ & 4,2 & 25,2 & 21,4 & 29,4 & 19,8 \\
\hline 5. & Zagađenje voda za piće & 5,5 & 23,1 & 24,8 & 31,5 & 15,1 \\
\hline 6. & Zagađenje reka i jezera & 2,1 & 15,1 & 21,0 & 35,7 & 26,1 \\
\hline 7. & $\begin{array}{l}\text { Zagađenje hrane } \\
\text { (pesticidi, herbicidi, konzervansi, GMO) }\end{array}$ & 3,4 & 17,2 & 26,0 & 34,5 & 18,9 \\
\hline 8. & Klimatske promene & 6,3 & 21,8 & 28,6 & 32,4 & 10,9 \\
\hline 9. & Devastacija i odumiranje šuma & 1.7 & 6,3 & 16,8 & 33,6 & 41,6 \\
\hline 10. & $\begin{array}{l}\text { Neadekvatno upravljanje komunalnim } \\
\text { otpadom }\end{array}$ & 3,8 & 15,6 & 27,3 & 34,0 & 19,3 \\
\hline 11. & $\begin{array}{l}\text { Degradacija obradivog zemljišta } \\
\text { (izgradnja industrijskih pogona, stanova, } \\
\text { kuća, puteva) }\end{array}$ & & & & \\
\hline
\end{tabular}

* 1 - veoma malo; 2 - malo; 3 - (o)srednje; 4 - mnogo; 5 - veoma mnogo.

Najmanje dominantne su frekvencije odgovora ("veoma malo" i "malo" - kolone 1 + 2): neadekvatno upravljanje komunalnim otpadom (t.10 $-8,0 \%$ ispitanika), ugroženost životne sredine od industrijskih postrojenja (t.3 - 13,0\% ispitanika) i opasan otpad i njegovo gomilanje (t.2 - 16,4\% ispitanika).

Relativno je visok procenat ispitanika koji su na tvrdnje odgovorili "(o)srednje" (kolona 3), a rezultati se kreću od $21,0 \%$ do $29,4 \%$, osim na tvrdnju o neadekvatnom upravljanju komunalnim otpadom za koju se izjasnilo $16,8 \%$ ispitanika.

Rangiranje stepena zabrinutosti za ekološke probleme (Tabela 2) izvršeno je u skladu sa rezultatima stepena (ranga) zabrinutosti u tri kategorije: ispitanike koji tvrde da su navedeni ekološki problemi "veoma malo" i "malo" zabrinjavajući (kolona 2), ispitanike koji tvrde da su navedeni ekološki problemi "(o)srednje" zabrinjavajući (kolona 3) i ispitanike koji tvrde da su navedeni ekološki problemi "mnogo" i "veoma mnogo" zabrinjavajući (kolona 4). Rangiranjem \% (procenta) ispitanika iz kolone 4 dobijeni su rangovi (kolona 5). Prvo mesto je neadekvatno upravljanje komunalnim otpadom (rang 1), na drugom mestu je zagađenje hrane (rang 2), a na trećem mestu je ugroženost životne sredine od industrijskih postrojenja (rang 3). Tri poslednja mesta, od 11 rangiranih ekoloških problema, su: zagađenje voda za piće (rang 9), zagađenje reka i jezera (rang 10) i devastacija i odumiranje šuma (rang 11).

Tabela 2 - Stepen/rang zabrinutosti za ekološke probleme

Table 2 - Degree/rank of concern for environmental problems

\begin{tabular}{|c|c|c|c|c|}
\hline $\begin{array}{c}\text { Redni } \\
\text { broj }\end{array}$ & malo & (o)srednje & mnogo & rang \\
\hline & $(1+2)$ & $(3)$ & $(4+5)$ & $(4+5)$ \\
\hline 1 & 2 & 3 & 4 & 5 \\
\hline 1. & 19,3 & 29,4 & 51,3 & 8 \\
\hline 2. & 16,4 & 25,2 & 58,4 & 4 \\
\hline 3. & 13,0 & 27,3 & 59,7 & 3 \\
\hline 4. & 17,6 & 25,6 & 56,8 & 5 \\
\hline 5. & 29,4 & 21,4 & 49,2 & 9 \\
\hline 6. & 28,6 & 24,8 & 46,6 & 10 \\
\hline 7. & 17,2 & 21,0 & 61,8 & 2 \\
\hline 8. & 20,6 & 26,0 & 53,4 & 6 \\
\hline 9. & 28,1 & 28,6 & 43,3 & 11 \\
\hline 10. & 8,0 & 16,8 & 75,2 & 1 \\
\hline 11. & 19,4 & 27,3 & 53,3 & 7 \\
\hline
\end{tabular}


Podaci u Tabeli 2 pokazuju da su ekološki problemi koji se odnose na prirodnu sredinu znatno manje zabrinjavajući od problema koje čovek sam proizvodi (otpad, zagađenje hrane). Hipotetički se može zaključiti da ispitanici prirodu (prirodno okruženje) smatraju još uvek ekološki zadovoljavajućim i da mnogi od spomenutih problema za njih danas nisu «mnogo» i «veoma mnogo» zabrinjavajući.

Pregled problema koji su "veoma malo i malo", "(o)srednje" ili "mnogo i veoma mnogo" zabrinjavajući dat je u Tabeli 3. Analiza percepcije ekoloških problema ustanovljena je i preko povezanosti regionalnih obeležja i odgovora ispitanika metodom hi-kvadrat testa na nivou značajnosti $p<0,01$. Procena ekoloških problema je različita i odražava specifičnost "razlika" regiona. Ispitanike u Istočnoj Srbiji, relativno, manje opterećuju ekološki problemi zagađenja voda, hrane i zemljišta (t. 5, t. 7, t. 11), a "jedini" ekološki problem o kojem se izjašnjavaju kao "mnogo" ili "veo- ma mnogo" zabrinjavajući je eksploatacija prirodnih resursa (t. 4). Ispitanici iz Beograda ekološke probleme najčešće ocenjuju kao "(o)srednje" (t. 3, t. 4 , t. 5, t .7), ili kao "mnogo" ili "veoma mnogo" zabrinjavajuće (t. 1, t. 2, t .6, t. 10, t. 11). Za stanovnike Vojvodine većina ekoloških problema je "mnogo" ili "veoma mnogo" zabrinjavajuća (t. 1, t. 3, t .4, t .5, t. 6, t. 7, t. 8, t. 9, t. 11).

Ekološki problemi i njihova procena danas su pesimističniji od onih pre 5 godina, jer ih ispitanici 2020. godine uglavnom percipiraju kao prosečno više zabrinjavajuće nego što je bio slučaj 2015. godine (Tabela 4). U svim situacijama kada je osetljivost na ekološki problem manje zabrinjavajuća (zagađenje vode za piće, devastacija i odumiranje šuma), odnosno kada se ekološki problemi percipiraju kao manje zabrinjavajući nego pre pet godina, to otvara problem ekološke senzibilnosti i šta (i ko) na njega suštinski utiče ili može da utiče.

Tabela 3 - Razlike u proceni ekoloških problema po regionima

Table 3 - Differences in the assessment of environmental problems by regions

\begin{tabular}{|c|c|c|c|c|}
\hline \multirow{2}{*}{\multicolumn{2}{|c|}{ Ekološki problemi }} & \multicolumn{3}{|c|}{ Procena stepena zabrinutosti } \\
\hline & & \multirow{2}{*}{$\begin{array}{c}\begin{array}{c}\text { veoma malo i } \\
\text { malo }\end{array} \\
\text { J. Srbija, } \\
\text { Z. Srbija }\end{array}$} & \multirow{2}{*}{$\begin{array}{c}\text { (o)srednje } \\
\text { C. Srbija, } \\
\text { I. Srbija }\end{array}$} & \multirow{2}{*}{$\begin{array}{c}\text { mnogo i } \\
\text { veoma mnogo } \\
\text { Beograd, } \\
\text { Vojvodina }\end{array}$} \\
\hline 1. & Zagađenje vazduha & & & \\
\hline 2. & $\begin{array}{l}\text { Opasan otpad i njegovo gomilanje } \\
\text { (industrijski I medicinski) }\end{array}$ & $\begin{array}{l}\text { J. Srbija, } \\
\text { Z. Srbija }\end{array}$ & $\begin{array}{l}\text { Vojvodina, } \\
\text { I. Srbija }\end{array}$ & $\begin{array}{l}\text { Beograd, } \\
\text { C. Srbija }\end{array}$ \\
\hline 3. & $\begin{array}{l}\text { Ugroženost životne sredine } \\
\text { od industrijskih postrojenja }\end{array}$ & $\begin{array}{l}\text { Z. Srbija, } \\
\text { J. Srbija }\end{array}$ & $\begin{array}{l}\text { Beograd, } \\
\text { I. Srbija }\end{array}$ & $\begin{array}{l}\text { C. Srbija, } \\
\text { Vojvodina }\end{array}$ \\
\hline 4. & $\begin{array}{l}\text { Eksploatacija prirodnih resursa } \\
\text { (ugalj, šume, voda, nafta) }\end{array}$ & $\begin{array}{l}\text { Z. Srbija, } \\
\text { C. Srbija }\end{array}$ & $\begin{array}{l}\text { Beograd, } \\
\text { J. Srbija }\end{array}$ & $\begin{array}{l}\text { Vojvodina, } \\
\text { I. Srbija }\end{array}$ \\
\hline 5. & Zagađenje voda za piće & $\begin{array}{l}\text { I. Srbija, } \\
\text { Z. Srbija }\end{array}$ & $\begin{array}{l}\text { Beograd, } \\
\text { J. Srbija }\end{array}$ & $\begin{array}{l}\text { Vojvodina, } \\
\text { C. Srbija }\end{array}$ \\
\hline 6. & Zagađenje reka i jezera & $\begin{array}{l}\text { Z. Srbija, } \\
\text { C. Srbija }\end{array}$ & $\begin{array}{l}\text { I. Srbija, } \\
\text { J. Srbija }\end{array}$ & $\begin{array}{l}\text { Beograd, } \\
\text { Vojvodina }\end{array}$ \\
\hline 7. & $\begin{array}{l}\text { Zagađenje hrane } \\
\text { (pesticidi, herbicidi, konzervansi, GMO) }\end{array}$ & $\begin{array}{l}\text { I. Srbija, } \\
\text { Z. Srbija }\end{array}$ & $\begin{array}{l}\text { Beograd, } \\
\text { J. Srbija }\end{array}$ & $\begin{array}{l}\text { Vojvodina, } \\
\text { C. Srbija }\end{array}$ \\
\hline 8. & Klimatske promene & $\begin{array}{l}\text { Beograd, } \\
\text { Z. Srbija }\end{array}$ & $\begin{array}{l}\text { I. Srbija, } \\
\text { C. Srbija }\end{array}$ & $\begin{array}{l}\text { Vojvodina, } \\
\text { J. Srbija }\end{array}$ \\
\hline 9. & Devastacija i odumiranje šuma & $\begin{array}{l}\text { Beograd, } \\
\text { Z. Srbija }\end{array}$ & $\begin{array}{l}\text { C. Srbija, } \\
\text { J. Srbija }\end{array}$ & $\begin{array}{l}\text { Vojvodina, } \\
\text { Z. Srbija }\end{array}$ \\
\hline 10. & $\begin{array}{l}\text { Neadekvatno upravljanje } \\
\text { komunalnim otpadom }\end{array}$ & $\begin{array}{l}\text { Vojvodina, } \\
\text { C. Srbija }\end{array}$ & $\begin{array}{l}\text { I. Srbija, } \\
\text { Z. Srbija }\end{array}$ & $\begin{array}{l}\text { Beograd, } \\
\text { J. Srbija }\end{array}$ \\
\hline 11. & $\begin{array}{l}\text { Degradacija obradivog zemljišta } \\
\text { (izgradnja ind. pogona, stanova, kuća, puteva) }\end{array}$ & $\begin{array}{l}\text { Z. Srbija, } \\
\text { I. Srbija }\end{array}$ & $\begin{array}{l}\text { J. Srbija, } \\
\text { C. Srbija }\end{array}$ & $\begin{array}{l}\text { Vojvodina, } \\
\text { Beograd }\end{array}$ \\
\hline
\end{tabular}

Za prikaz razlika tokom petogodišnjeg perioda su korišćene frekvencije dela petostepene lestvice (skale) vrednovanja (1-5), odnosno zbir najviših vrednosti za dve ocene (4+5). U oba istraživanja, značajan broj ispitanika (od ukupno 236) procenjuje ekološke probleme veoma zabrinjavajućim (M). Za ovakvu procenu u 2015. godini manje od $50 \%$ ispitanika opredelilo se za samo tri problema: zagađenje voda za piće 
$(48,2)$, zagađenje reka i jezera $(46,6 \%)$ i devastacija i odumiranje šuma (43,3\%), kao i u 2020 godini.

Distribucija frekvencije pokazuje da značajno manji broj ispitanika očekuje bolje stanje za pet godina, kao i da je visok procenat onih koji su očekivali lošije stanje za pet godina. Broj ispitanika koji ekološke probleme ocenjuju zabrinjavajućim (M) u 2020. godini je značajno veći od broja ispitanika koji su 2015. godine očekivali "bolje" i "mnogo bolje" (Bo) stanje za pet godina.

Komparativna analiza stepena zabrinutosti za ekološke probleme 2015. i 2020.godine pokazuje svojevrsni pesimizam u očekivanjima, a realizam u aktuelnom procenjivanju. Istraživanja su pokazala hipotetičku zakonitost: kada su problemi više zabrinjavajući, onda indiciraju veću senzibilnost. Podaci iz prezentovanih istraživanja 2015.i 2020. godine su indikativni za ekološku senzibilnost. Ekološki problemi u Srbiji dobili su "pravo građanstva" tek osamdesetih i devedesetih godina XX veka, kao rezultanta povećane društvene aktuelnosti u svetu, ali i kod nas. Preovlađujući razlog za istraživanje ekoloških problema je teorijski utemeljeno znanje o ekološkoj krizi i posledicama zagađenja životne sredine, ali i istovremeni uticaj na pitanja ekonomskog razvoja (Ristić i dr.,2019). To je prvenstveno uticalo na značajniji angažman nauke u sektoru zaštite životne sredine i iskorak ekoloških problema prirodnih nauka, kada ekološki fenomeni ulaze u naučni korpus društvenih i humanistističkih nauka, pre svega, zbog empirijskih istraživanja društvene percepcije ekoloških problema.

Tabela 4 - Procena stepena zabrinutosti za ekološke probleme 2015. i 2020.godine

Table 4 - Assessment of the degree of concern for environmental problems in 2015 and 2020

\begin{tabular}{|c|l|c|c|c|c|}
\hline \multirow{2}{*}{$\begin{array}{c}\text { Red br. } \\
\text { komponente }\end{array}$} & \multicolumn{1}{|c|}{ Sadržaj tvrdnje (varijable) } & \multicolumn{3}{|c|}{ procena 2015. g. procena 2020. g. } \\
\cline { 4 - 5 } & & $\mathrm{N}$ & \multicolumn{2}{|c|}{ Za 5 godina } & \multirow{2}{*}{$\mathrm{M}$} \\
& & & Lo & Bo & \\
\hline 1. & Zagađenje vazduha & 51,3 & 46,2 & 16,8 & 58,8 \\
\hline 2. & $\begin{array}{l}\text { Opasan otpad i njegovo gomilanje } \\
\text { (industrijski i medicinski) }\end{array}$ & 58,4 & 48,3 & 18,9 & 60,9 \\
\hline 3. & $\begin{array}{l}\text { Ugroženost životne sredine } \\
\text { od industrijskih postrojenja }\end{array}$ & 59,7 & 42,4 & 23,1 & 61,7 \\
\hline 4. & $\begin{array}{l}\text { Eksploatacija prirodnih resursa } \\
\text { (ugalj, šume, voda, nafta) }\end{array}$ & 56,8 & 50,4 & 14,7 & 57,5 \\
\hline 5. & Zagađenje voda za piće & 48,2 & 46,2 & 18,9 & 48,3 \\
\hline 6. & Zagađenje reka i jezera & 46,6 & 47,4 & 21,0 & 46,2 \\
\hline 7. & $\begin{array}{l}\text { Zagađenje hrane } \\
\text { (pesticidi, herbicidi, konzervansi, GMO) }\end{array}$ & 61,8 & 39,9 & 22,2 & 71,4 \\
\hline 8. & Klimatske promene & 53,4 & 7,8 & 8,4 & 65,1 \\
\hline 9. & Devastacija i odumiranje šuma & 43,3 & 50,4 & 14,7 & 39,9 \\
\hline 10. & $\begin{array}{l}\text { Neadekvatno upravljanje komunalnim } \\
\text { otpadom }\end{array}$ & 75,2 & 52,5 & 23,1 & 79,8 \\
\hline 11. & $\begin{array}{l}\text { Degradacija obradivog zemljišta } \\
\text { (izgradnja industrijskih pogona, stanova, } \\
\text { kuća, puteva) }\end{array}$ & 53,4 & 46,2 & 12,6 & 58,8 \\
\hline
\end{tabular}

M - "mnogo" zabrinjavajuće (mnogo + veoma mnogo); Lo - stanje će biti lošije/gore; Bo - stanje će biti bolje.

Istraživanja odnosa između tehnološkog razvoja i percepcije ekoloških problema u svetu obeležila su dva perioda. Najznačajniji predstavnik prvog perioda, sredina devedesetih godina dvadesetog veka, je Ronald Inglehart, zastupnik teorije ekološke modernizacije, koji ekonomski razvoj vezuje sa očuvanjem životne sredine. Inglehartova studija "Javna podrška zaštiti životne sredine: Objektivni problemi i subjektivne vrednosti u 43 društva" snažno promoviše princip da se ekološki stavovi razvijaju paralelno sa društvenim razvojem, odnosno procesima modernizacije (Inglehart, 1995). Drugi period, od 2000. godine do danas, karakteriše prikupljanje podataka iz serije međunarodnog programa društvenih istraživanja (ISSP - Internacional Social Survey Program) sprovedenih 1993., 2000., i 2010. godine. Ova istraživanja na precizniji način utvrđuju determinisanost ekoloških stavova od pojednostavljenih tvrdnji o bogatstvu i globalizaciji, koji su zastupljeni devedesetih godina dvadesetog veka. Dobar primer za ovaj pri- 
stup su istraživanja koja su sproveli Francen i Meyer (2010) i Givens i Jorgenson (2011). Istraživanja Francena i Meyera pokazuju da su razlike među zemljama značajno manje od onih unutar samih zemalja (Francen and Meyer, 2010). Istraživanja Givensa i Jorgensona dokazuju suštinsku povezanost između društvenog (nacionalnog) bogatstva (BDP-a) i brige za zaštitu životne sredine (Givens and Jorgenson, 2011).

Ekološka modernizacija je nametnula potrebu da se razobliči hegemonija ekonomske sfere I emancipuje ekološka racionalnost. Industrijska proizvodnja i konzumerizam u potrošnji, koji počivaju isključivo na ekonomskoj racionalnosti i logici kapitala, moraju se suočiti sa ekološkom racionalnošću (Mol et al., 2013). U ekološkoj sferi jačaju pojedini instituti: studije o proceni uticaja na životnu sredinu, a industrija usvaja modele cirkularne ekonomije (Vukadinović, 2018). Globalni trendovi, posebno klimatske promene i pristup resursima, suštinski će uticati na kvalitet života i ukupnu ekološku bezbednost (Radić i dr., 2020). U ovakvim scenarijima, ekološki stavovi su odraz optimizma za značajnije sprovođenje institucionalnih reformi.

U Srbiji nema sistemskog istraživanja problema ekološke senzibilnosti, što implicira potrebu za uspostavljanje istraživanja percepcije problema u zaštiti životne sredine, odnosno uspostavljanje ekološkog barometra, kao instrumentarijuma za utvrđivanje realn(ij)e percepcije ekoloških problema.

\section{ZAKLJUČAK / CONCLUSION}

Antropocentrizmu (homocentrizmu) su, kako korelativna analiza socijalno-ekološke orijentacije i ekološke zabrinutosti precizno pokazuje, skloni ispitanici koji ekološke probleme zagađenja vode za piće (t. 5), zagađenje reka i jezera (t. 6) i degradacije obradivog zemljišta (t. 11) smatraju za više zabrinjavajuće probleme u Srbiji, kao i oni ispitanici koji smatraju da su zagađenje vazduha (t. 1), zagađenje hrane (t. 7), klimatske promene (t. 8) i neadekvatno upravljanje komunalnim otpadom (t.10) ekološki manje zabrinjavajući problemi.

Tehnocentrizmu (tehnicizmu) su skloniji ispitanici koji smatraju da je neadekvatno upravljanje komunalnim otpadom (t.10) više zabrinjavajući ekološki problem, kao i ispitanici koji zagađenje vazduha (t. 1), gomilanje opasnog otpada (t. 2), ugroženost životne sredine od industrijskih postrojenja (t. 3), eksploataciju prirodnih dobara (t. 4), zagađenje vode za piće (t. 5), zagađenje reka i jezera (t. 6) i degradaciju obradivog zemljišta (t. 11) smatraju kao manje zabrinjavajuće ekološke probleme u Srbiji.

Ekocentrizmu (naturalizmu) naginju i iskazuju svoju sklonost ispitanici koji smatraju da su zaga- đenje vazduha (t. 1), zagađenje hrane (t. 7), klimatske promjene (t. 8) i neadekvatno upravljanje komunalnim otpadom (t. 10) ekološki više zabrinjavajući problemi u Srbiji.

Uporedna analiza rezultata istraživanja, obavljenih 2015. i 2020. godine, u proceni ekoloških problema u bliskoj budućnosti, pokazuje da ispitanici iskazuju pesimizam i očekuju da će se ekološki problemi uglavnom povećati. Nivo senzibilnosti na ekološke probleme je konstantan i ne pokazuje trend opadanja. Ako se zadrži realna osnova $i$ iskazani pesimizam za percipiranje ekoloških problema, to bi mogla da bude dobra osnova za ekološku osetljivost (senzibilnost), ali i za lični angažman pojedinca u sistemu zaštite životne sredine.

Ne treba isključiti značaj novih saznanja o stanju životne sredine u našem okruženju i šire, jer ona mogu da utiču na percepciju ekoloških problema u Srbiji. Uloga medija i javnosti, kada su informacije realne, su od velikog značaja, jer mogu delovati na povećanje perceptivne adaptabilnosti na ekološke probleme.

Ovaj rad ukazuje na potrebu uspostavljanja ekološkog barometra, odnosno sistemskog istraživanja percepcije javnosti o ekološkim problemima i ekoIoškoj politici u Srbiji. Ekološka realnost nije privilegija i potreba pojedinaca ili pojedinih institucija, već društveni i kulturni entitet prema kojem se tako treba i odnositi.

\section{LITERATURA / REFERENCES}

[1] Adžemović, M. (2016). Ekološke determinante ekonomije u preoblikovanju ekološko-ekonomskih instrumenata zaštite životne sredine, Univerzitet Singidunum, Fakultet za primenjenu ekologiju FUTURA, Beograd. Pristupljeno 18. aprila 2021., na http://singipedia.singidunum .ac.rs/izdanje/42513-ekoloske-determinanteekonomije-u-preoblikovanju-ekolosko-ekonomskihinstrumenata-zastite-zivotne-sredine

[2] Adžemović, M. (2019). Ekološka bezbednost. Univerzitet Singidunum, Beograd. Pristupljeno 18. aprila 2021., na http://master.crnarupa.singidunum.ac.rs/20202021/Zivotna+sredina+i+odrzivi+razvoj/Ekoloska $\% 20$ bezbednost $\% 20$ \%20Mesud\%20Adzemovic/

[3] Franzen, A., Meyer, R. (2010). Environmental Attitudes in Cross-National Perspective: A Multilevel Analysis of the ISSP 1993 and 2000. European Sociological Review, 26(2), 219-234. https://doi.org/10.1093/esr/jcp018

[4] Givens, J.E., Jorgenson, A.K. (2011). The Effects of Affluence, Economic Development, and Envir- 
onmental Degradation on Environmental Concern: A Multilevel Analysis. Organization \& Environment, 24(1), 74-91.

https://doi.org/10.1177/1086026611406030

[5] Inglehart, R. (1995). Public support for envir onmental protection: Objective problems and subjective values in 43 societies. PS: Political science and politics, 28(1), 57-72. https://doi.org/10.2307/420583

[6] Adžemović, M.R., Šašić Ivanović, A.Z., Nikolić, D.M., Aleksić, J.D. and Stevanović, R.M. (2017), Redesigning current instruments as a precondition for a more effective environmental protection, Chemical Industry, 71(4): 343-350. DOI: 10.2298/HEMIND160620045A.

[7] Mol, A. P. J., Spaargaren, G., Sonnenfeld, D. A. (2013). Ecological modernization theory: Taking stock, moving forward. In: S. Lockie, D. A.
Sonnenfeld, D. Fisher (Eds.), Routledge international handbook of social and environmental change (pp. 15-30). London, New York: Routledge/Taylor \& Francis Group.

[8] Radić, N., Stevanović, M., Radić, V. (2020), Životna sredina i resursi - globalni trendovi i odrazi na ekonomiju do 2050. godine, Ecologica, 27(97), 141-146

[9] Vukadinović, P. (2018), Ekologija između linearne i cirkularne ekonomije, Ecologica, 24(90), 231236

[10] Ristić, K., Lukinović, M., Kovačević, Ž. (2019), Ekologija, ekonomija i oporezivanje, Ecologica, 26(94), 289-293

[11] Stevanović, S., Marinković, G., Minović, J. (2018), Ekološke dažbine u Srbiji kao ekonomski instrument zaštite životne sredine, Ecologica, 25(92), 857-862. 